\title{
(Ad)dressing the female body
}

\section{ABSTRACT}

This visual essay presents a body of work that uses a 'language of flesh' and fabric to make explicit the relationship between the body, image and our increasingly material world. Recognizing that our skin is a site of inscription for social and cultural ideals, it considers how these images have been internalized and appropriated onto the body. As the temptation to sculpt our body through clothing and cosmetic surgery becomes increasingly pressing, it is important to pose questions as to how and why we are fashioned. Weaving together feminist concerns, and touching upon (syn)aesthetic discourses to frame and embellish these samples of practice, it is hoped that certain assumptions about the female body are ruptured. Using the site/sight of the body to try and expose these fabrications, I have created these 'articulate' costumes to unpick them.

These costumes are critical as they deny their conventional function, instead opening up and celebrating the visceral, living body. These subversions, in undermining typical narratives of fashion and flesh, create a space to (re)present this body; allowing it to speak for itself. In (ad)dressing the female body, I use the (un)dress to redress our corporeal and cerebral understanding of it.

\section{KEYWORDS}

female body explicit body 'language of flesh' image

skin

suture

(syn)aesthetic disintegrating dress 
My body is my material. Unable to cut myself off, I live with and shape it. My experiences have been the catalyst to create this 'explicit body' of work; in the hope of liberating the female figure from some of the claustrophobic ideals that increasingly try to define and refine it.

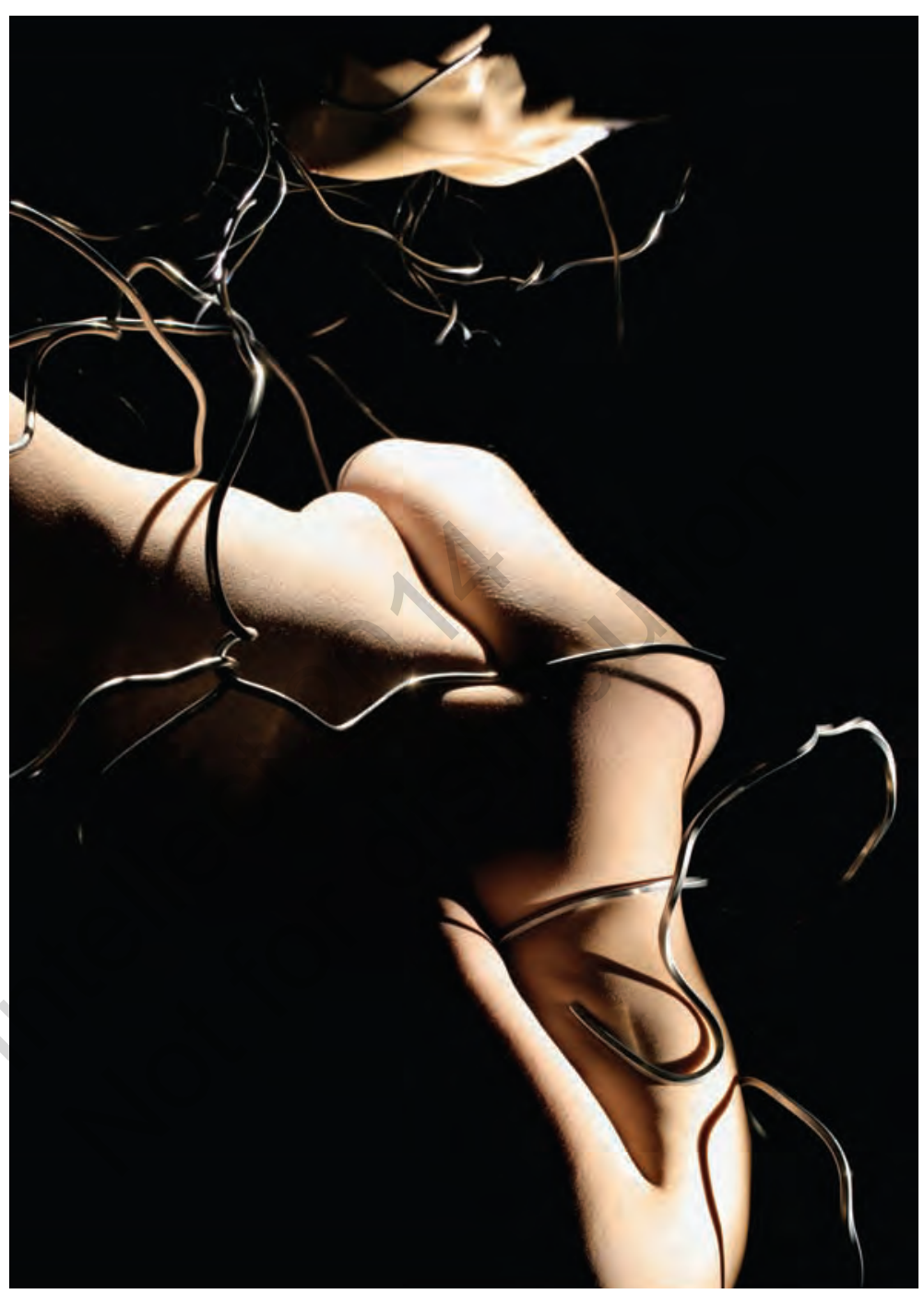

Figure 1: Her|She|Me, Madaleine Trigg (C) 2007.

Unfolding the body, as if pulling back velvet curtains to expose a stage, the performance artists... peel back layers of signification that surrounds their bodies like ghosts at a grave.

Peeling at signification, bringing ghosts to visibility, they are interested to expose not an originary, true, or redemptive body, but the sedimented layers of signification themselves.

(Schneider 1997: 2) 
(Ad)dressing the female body

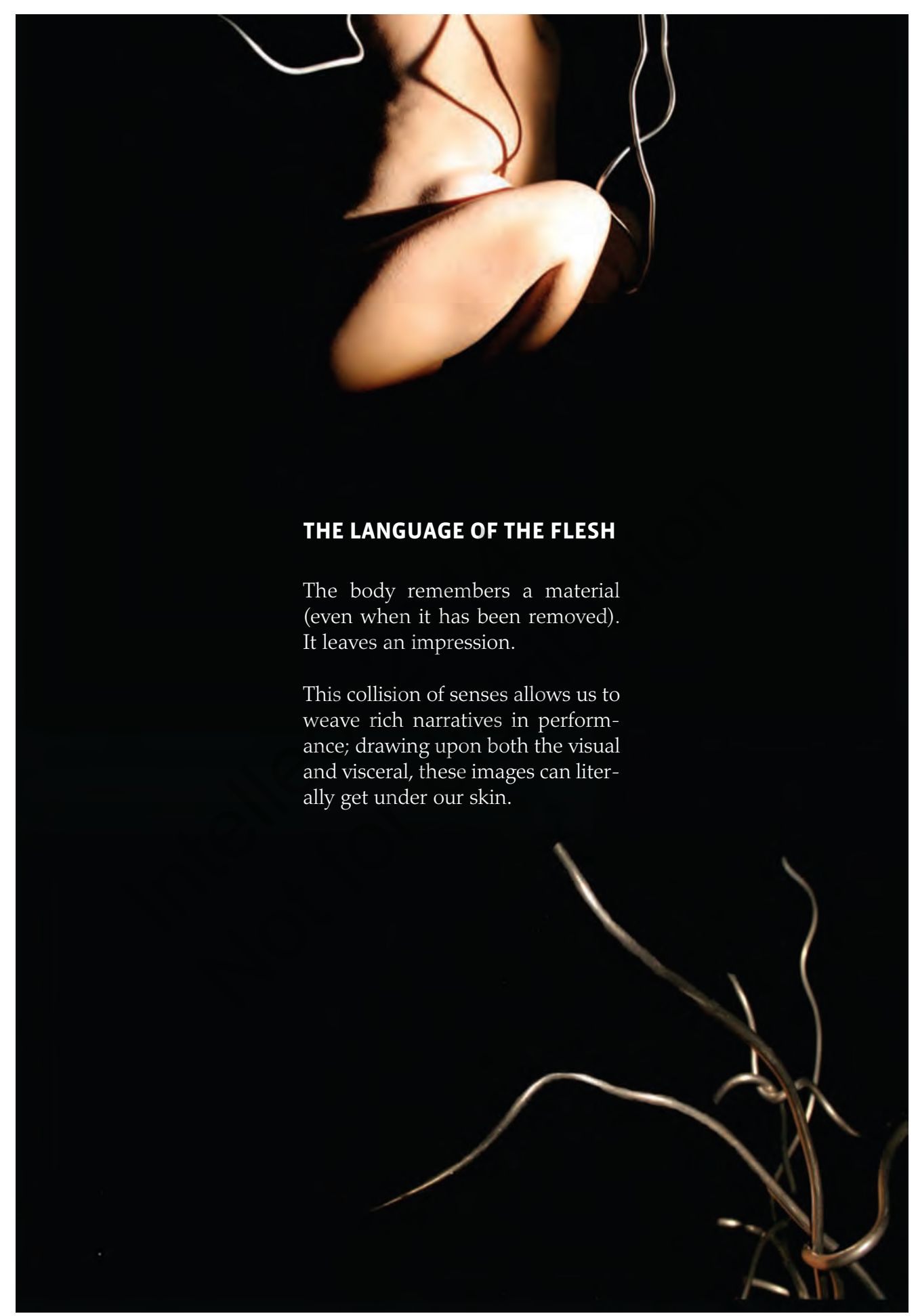

Figure 2: Umbra, Madaleine Trigg ( 2009. 


\section{THE SKIN WE ARE IN}

The relationship between the body, skin and fabric has always been closely interwoven. Due to its proximity and tactile nature, drapery and clothing have been considered a 'second skin', and whilst there is a functional element we cannot deny its role as a social signifier. As Kaja Silverman elaborates, clothing is 'necessary to make the body 'culturally visible... clothing draws the body so that it can be culturally seen and articulates it in a meaningful form' (Doy 2002: 61). This association has become increasingly complex in our postmodern society, especially in relation to the '(de) signs' of the fashion, cosmetic and surgical industries. This emphasis on the surface naturally privileges sight and the 'the seductive power of the image is an important stimulus in the construction of contemporary ['beauty'] myth[s]. The construction of the image is, at the same time, the construction of the body' (Calefato 2004: 74).

The interaction between bodies and their materiality are visible in Felt Me. Wrapped in two kilos of white wool, the audience is invited to feel me and, in the process, fashion a felt dress on me. This intimate encounter is significant as through the body we make sense of it. Felt Me was created during a residency in Freising, a small German town that was historically renowned for the production of felt. This industry has now faded and the performance resurrects this knowledge, commemorating this craft by sharing it with the local community. It is also through our touch, that we are touched. 
As the focus on the external body becomes increasingly internalized, it is important to expose it. In Sutre, the use of costume literally dissects it.

In Haptic Visuality, Bouchard asserts that viewing 'the anatomized and opened body destabilizes and even ruptures the representational strategies within which it is situated' (2013: 163). Whilst she is describing 'The incredulity of Saint Thomas' as he probes Christ's resurrection wounds, I can relate to her material.

The whole painting is compositionally focused on the physicality of the surfaces, from the detailed depictions of draped and falling fabric to the various exposed areas of flesh ... This concentration on materiality provokes in the spectator an awareness of tactile experience ... Suddenly the viewer is plunged deeper than the surface into the wound that opens itself beneath or beyond ... the image instigates a slide in perception between touch and sight.

(Bouchard 2013: 170)

As my dress slowly disintegrates, it grafts itself to the body. In extending and opening up the body, it revels in the revealing folds of flesh and fat. This costume is critical as it does not try to perfect the body. Instead it probes deeper, this prosthesis revealing the raw reality. Subversively, the costume no longer conceals this messy, fleshy body, but lays it bare for all to see.

For this body, 'the object of salvation' is not necessarily found in the sewing together of fabric and flesh. This costume lives but only for the duration of the performance.

After that, it is shed. Shedding some light on one layer of signification that surrounds us.

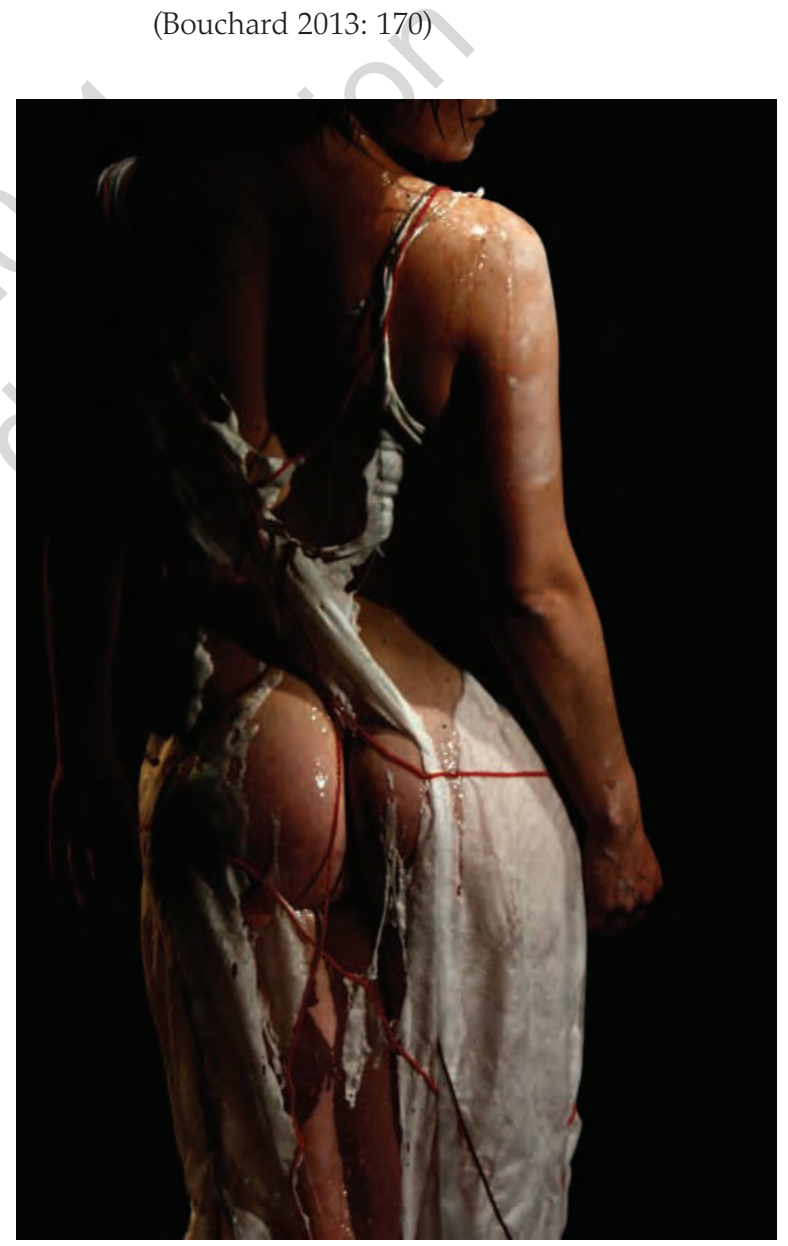

Figure 4: Sutre, performance still, Jemima Yong ( 2009 


\section{REFERENCES}

Baudrillard, Jean (1998), 'The finest consumer object: The body', The Consumer Society. Myths and Structures, London: Sage.

Bouchard, Gianna (2013), Haptic Visuality: The Dissective View in Performance, Bristol: Intellect.

Doy, Gen (2002), Drapery. Classicism and Barbarism in Visual Culture, London: I. B Tauris.

Machon, Josephine (2009), (Syn)aesthetics: Redefining Visceral Performance, Hampshire: Palgrave Macmillan Ltd.

Oddey, Alison and White, Christine (eds) (2013), Modes of Spectating, Bristol: Intellect.

Schneider, Rebecca (1997), The Explicit Body in Performance, London: Routledge.

Wolf, Naomi (1991), The Beauty Myth, London: Vintage.

\section{SUGGESTED CITATION}

Trigg, M. (2014), '(Ad)dressing the female body', Scene, 2: 1+2, pp. 127-132, doi: 10.1386/scene.2.1-2.127_1

\section{CONTRIBUTOR DETAILS}

Madaleine is a performance artist and photographer. Her practice predominantly explores the image and issues of the female body; using sculptural materials, costumes, movement and photography to (re)present this body. Madaleine's solo, Sutre, premiered at SPILL Festival's National Platform in 2009 and has since been performed at Vitoria's International Theatre Festival (Spain), BAC, Shunt and WrongWeather Gallery (Porto). In collaboration with the renowned holographic company Musion, Madaleine transformed the piece into a 3D projection, which was exhibited at the 2011Kinetica Art Fair. Sutre represented the United Kingdom in the 'Extreme Costume Exhibition' at the 2011 Prague Quadrennial and more recently was longlisted for the 2013 Aesthetica Art Prize. Sutre was also exhibited at the Critical Costume symposium, accompanied by a visual presentation. Madaleine's work has been included in Spill Festival's Publication: On agency, The Disappearing Stage: Reflections on the 2011 Prague Quadrennial and the Aesthetica Art Prize 2013 Catalogue. Madaleine's photographic practice experiments with performances in darkrooms, camera-less photography and alternative printing processes. This enables her to expand upon her material concerns by creating images on materials as diverse as wood, metal and fabric. Madaleine is a lecturer on B.A. Performance Arts and M.A. Scenography at the Royal Central School Of Speech and Drama.

E-mail: madaleine.trigg@cssd.ac.uk

Madaleine Trigg has asserted her right under the Copyright, Designs and Patents Act, 1988, to be identified as the author of this work in the format that was submitted to Intellect Ltd. 